\title{
Prevalencia de anemia infecciosa equina en caballos de tracción en el municipio de Florencia (Caquetá)
}

\section{Equine infectious anemia prevalence in urban pulling horses in the municipality of Florencia (Caquetá)}

Fecha de recepción: 14 de abril de 2016

Fecha de aceptación: 19 de junio de 2016

\author{
Beatriz Elena Patiño-Quiroz ${ }^{1}$ \\ Nicolás Ernesto Baldrich-Romero ${ }^{2}$ \\ Juan Carlos Caicedo-Robayo ${ }^{3}$ \\ Harrinson Ome-Peña ${ }^{4}$ \\ Juan Camilo Murillo-Rojas ${ }^{5}$
}

\section{Resumen}

En el estudio se evaluó la prevalecía de anemia infecciosa equina (AIE) en los caballos de tracción en el municipio de Florencia, buscando relación por sexo, edad, condición corporal y distribución por comunas. Para ello se recolectaron 128 muestras de sangre de equinos (103 machos y 25 hembras) que asistieron a 4 brigadas de salud animal realizadas por el semillero de investigación en equinos "SIEQUUS", de la Universidad de la Amazonia, durante el periodo comprendido entre mayo de 2014 y diciembre de 2015. Las muestras fueron analizadas en laboratorio con la prueba de inmunodifusión en agar gel. Se realizó análisis estadístico descriptivo y una prueba Chí cuadrado $(\mathrm{P}<0.05)$. Los datos muestran la prevalencia encontrada de AIE, determinando que el $26 \%$ de los animales eran positivos a la enfermedad (el $31.07 \%$ de los machos y el $4 \%$ de las hembras). Referente a la condición corporal, 21 equinos fueron clasificados en el grado 2 , y el $47.62 \%$ de ellos resultaron positivos a AIE; en el grado 3 se encontró la mayor población (82 equinos), con el $18.29 \%$ positivos, y en el grado 4, 25 animales, con el $17.97 \%$ positivos; se encontró relación significativa entre la condición corporal y la prevalencia de AIE. La prevalencia en los animales menores de 5 años $(<5)$ fue del $5 \%$; en los mayores de 10 años (>10) fue del $14.29 \%$, y en los animales entre 5 y 10 años fue considerablemente mayor, el $33.33 \%$. Las condiciones ambientales y socioeconómicas facilitan la transmisión del virus entre los caballos del mismo gremio y con cualquier sistema de manejo y producción equina de la zona, lo que generaría pérdidas económicas y de semovientes de importancia para el sector equino.

Palabras clave: AIE; anemia infecciosa equina; equinos.

1 Esp. Universidad de la Amazonia (Florencia-Caquetá, Colombia). b.patino@udla.edu.co.

2 Universidad de la Amazonia (Florencia-Caquetá, Colombia).n.baldrich@udla.edu.co.

3 Universidad de la Amazonia (Florencia-Caquetá, Colombia).

4 Universidad de la Amazonia (Florencia-Caquetá, Colombia).

5 Universidad de la Amazonia (Florencia-Caquetá, Colombia). 


\begin{abstract}
In the study, was evaluated the prevalence of equine infectious anemia (EIA) in traction horses in the municipality of Florencia, looking for relationship by sex, age, body condition and racial communes. 128 blood samples were collected from horses (103 males and 25 females) who attended four animal health brigades carried out by the hotbed research in horses "SIEQUUS" of the University of Amazonia, during the period between May 2014 and December 2015. The samples were analyzed in laboratory with agar gel immunodiffusion test. Descriptive statistical analysis and chi-square test $(P<0.05)$ was performed. The data show the prevalence found IEA, determining that $26 \%$ of the animals were positive to the disease (31.1\% of males and $4 \%$ of females). Regarding body condition, 21 horses classified in grade 2 , and $47.62 \%$ of them tested positive for EIA; in grade 3 were found the largest population (82 horses), with positive $18.29 \%$, and grade 4, 25 animals with positive $17.97 \%$; significant relationship between body condition and the prevalence of IEA was found. The prevalence in animals under 5 years $(<5)$ was $5 \%$; in over 10 years ( $>10$ ) was $14.29 \%$, and animals between 5 and 10 years was considerably higher, 33.33 $\%$. Environmental and socio-economic conditions facilitate transmission of the virus between horses of the same trade and any equine management system and production in the area, which would generate economic and livestock of importance to the equine industry losses.
\end{abstract}

Keywords: EIA; Equine Infectious Anemia; equines. 


\section{Introducción}

La Anemia Infecciosa Equina (AIE) es una enfermedad producida por un Lentivirus de la familia Retroviridae, el cual afecta estrictamente a mamíferos de la familia Equidae y está estrechamente relacionado con otros virus del mismo género causantes de inmunodeficiencia en bovinos, felinos y humanos (tipo 1 y 2$)(1,2)$.

La AIE tiene tres formas de presentación: aguda, con fiebre intermitente, depresión, petequias, debilidad progresiva, caquexia, anemia, edema en hombros, pecho y abdomen o muerte repentina; subaguda, con fiebre, depresión, anemia, linfoadenopatía, petequias, edema, emaciación y, esporádicamente, alteraciones neuronales, y crónica de baja concentración virémica, con pocos signos clínicos, fiebre y pérdida de peso (3, 4). La presentación clínica varía dependiendo del estado inmunológico del animal, de la virulencia y la dosis infectante del virus (5).

La transmisión del virus se da por contacto de un caballo sano con la sangre de otro infectado, ya sea por medio de la picadura de vectores como el tábano (Tabanussp.), la mosca de establos (Stomoxyscacitrans) (6) y, potencialmente, los mosquitos (7); por iatrogenia o por infección transplacentaria $(8,9)$.

El primer reporte de la enfermedad data del año 1843, en Francia (7); en Colombia fue descrita por primera vez en el departamento de la Guajira, en 1948, y el Instituto Colombiano Agropecuario (ICA) inició estudios para el diagnóstico en el año 1965. Cabe mencionar que el diagnóstico de la AIE no fue posible hasta 1970, cuando Leroy y Coggins describieron una prueba para detectar antígenos específicos cuyo núcleo proteico (p26) fue identificado como el anticuerpo; esta prueba de inmunodifusión en agar gel (AGID, por sus siglas en inglés), Ilamada "de Coggins", es reconocida internacionalmente como la más eficiente hasta la fecha.

La Organización Mundial de Sanidad Animal (OIE) establece, en el código sanitario para los animales, algunas recomendaciones para que las autoridades veterinarias exijan la presentación de un certificado que acredite que los animales movilizados no presentan ninguna sintomatología relacionada con la AIE, y deben respaldar el diagnóstico con pruebas de laboratorio no mayores a 90 días (10).

En Colombia, la resolución del ICA 676 de 2015 (11) es la norma que regula y establece las medidas sanitarias para la prevención de AIE); tal resolución determina que debido a la facilidad de transmisión de enfermedades infecciosas, dentro de las que se encuentra la AIE, en la movilización de équidos se requiere contar con la respectiva Guía Sanitaria de Movilización Interna (GSMI) realizada en sangre, en el laboratorio, por la única prueba serológica admitida oficialmente para el diagnóstico de la AIE, que es la de AGID o de Coggins.

\section{Materiales y métodos}

el presente estudio fue realizado durante el periodo comprendido entre mayo de 2014 y diciembre de 2015, en la ciudad de Florencia, departamento del Caquetá, ubicada en las coordenadas $1^{\circ} 36^{\prime} 51^{\prime \prime}$ latitud norte y $75^{\circ} 36^{\prime} 42^{\prime \prime}$ longitud oeste, al sur de Colombia, en la región amazónica, sobre la estribación oriental de la cordillera de los Andes, con altitud media de $242 \mathrm{msnm}$, precipitación media anual de $3840 \mathrm{~mm}$, temperatura entre 25 ${ }^{\circ} \mathrm{C}$ y $35{ }^{\circ} \mathrm{C}$ y humedad relativa superior al $80 \%$ (12).

Este proyecto fue avalado por el Comité de Ética, Bioética y Bienestar Animal de la Universidad de la Amazonia, por medio del acta 21 de 2014, donde se determinó que el grado de incomodidad es menor y que el estudio aportaría para identificar el estrés de los equinos positivos a la enfermedad.

Los datos se analizaron mediante estadística descriptiva con prueba de Chí cuadrado, para establecer la relación de la presencia del virus por sexo y edad; los equinos fueron agrupados en: menores de $5(<5)$, de 5 a $10(5-10)$ y mayores de 10 (>10), con condición corporal clasificada en escala de: 1-5 (1: caquéctico, 2: delgado, 3: normal, 4: sobrepeso y 5: obeso) (13) y distribución por comunas del municipio, las cuales se interpretaron por medio de tablas y gráficas de barras. 
El Semillero de Investigación en Equinos (SIEQUUS), de la Universidad de la Amazonia, convocó, mediante volantes, a las personas que utilizan equinos como tracción de vehículos, en el municipio de Florencia, a cuatro brigadas de salud animal, que se realizaron entre mayo de 2014 y diciembre de 2015; a estas asistieron 128 equinos distintos de raza Criollo Colombiano: 103 machos y 25 hembras, que representan el $29.16 \%$ del total de censo equino urbano (439 semovientes), reportado en el municipio por la Secretaría de Transporte y Movilidad.

La recolección de la muestra se hizo mediante venopunción de la yugular, con sistema vacutainer, según el protocolo planteado por Orsini y Divers (2000) (14); se extrajo sangre de cada animal en tubos de muestra tapa roja debidamente rotulados; las muestras fueron procesadas mediante prueba de AGID (9), en el laboratorio del Almacén Insuagro Ltda., con certificación ICA para diagnóstico de AIE No. 3759 de 2014 (15).

\section{Resultados y discusión}

Al finalizar el estudio se encontró que la prevalencia de AIE en la población analizada fue del $26 \%$, resultado bastante alto si se compara con los estudios en otros municipios y departamentos de Colombia como: Bogotá D.C. (1.67 \% en 2013) (16); San Martin, Guamal, Restrepo, Cumaral y Paratebueno, en el Meta $(13.2 \%$ en 2008) (17); Montería, en equinos de pesebreras en $2000(19.72 \%)(18)$, y Chocó y Guajira, en 2005 (8.06 \%) (19). Posiblemente, esta marcada variación se deba a las condiciones ambientales del piedemonte amazónico, por presencia de aguas lénticas, encharcamientos y vegetaciones rastreras o arbustivas, que facilitan la presencia y proliferación de vectores de la enfermedad (20) y la aglomeración en puntos de concentración, que agilizan la transmisión. En Poconé, estado de Mato Grosso, Brasil, se encontró una prevalencia del $31.5 \%$, indicándose que en zonas inundables los equinos eran 146.4 veces más propensos a presentar seropositividad a AIE (21), mientras en regiones más secas las prevalencias son menores, como Curitiba (1.03\%) y Rio de Janeiro $(0.74 \%)$ (22).

Una prueba Chi cuadrado indicó una relación significativa $(P<0.05)$ entre el sexo de los equinos y la prevalencia del virus. El $31.06 \%$ de los machos presentó seropositividad a la AIE, mientras que para las hembras fue del $4 \%$ (Tabla I).

Tabla I. Distribución de equinos positivos y negativos por sexo

\begin{tabular}{|c|c|c|c|}
\hline SEXO & NEG & POS & TOTAL \\
\hline Machos & 71 & 32 & 103 \\
\hline Hembras & 24 & 1 & 25 \\
\hline
\end{tabular}

Estos resultados coinciden con los reportados para la zona del Pantanal (Mato-Grosso do Sul, Brasil), donde la seroprevalencia a la AIE fue significativamente mayor en machos (14\%) que en hembras (10\%). Los autores sugieren que estas diferencias fueron debidas a la predilección de los propietarios por el uso de machos para las labores, lo que incrementa su inventario en la población y, por lo tanto, aumenta la probabilidad de contagio (23). En el presente estudio, los machos constituyeron el $80.4 \%$ de la población analizada, coincidiendo con lo reportado en el estudio en Pantanal (23). En contraste, en estudios realizados en Pocone (Mato Grosso, Brasil) (21) no encontraron relación entre el sexo y la prevalencia. Estos autores estudiaron 3285 equinos, pero no reportan porcentaje de machos y hembras.

Al discriminar por condición corporal (CC) (Figura 1) se determinó que 21 semovientes fueron clasificados en grado 2, de los cuales el $47.62 \%$ resultaron positivos a la prueba de AGID; en el grado 3 se encontró la mayor población, con 82 equinos, de los cuales el $18.29 \%$ fueron positivos a AIE, y en el grado 4 se atendieron 25 animales, y el $17.97 \%$ de ellos resultaron infectado. Con la prueba Chí cuadrado $(\mathrm{P}<0.05)$ se encontró relación significativa entre la condición corporal y la prevalencia de AIE. 


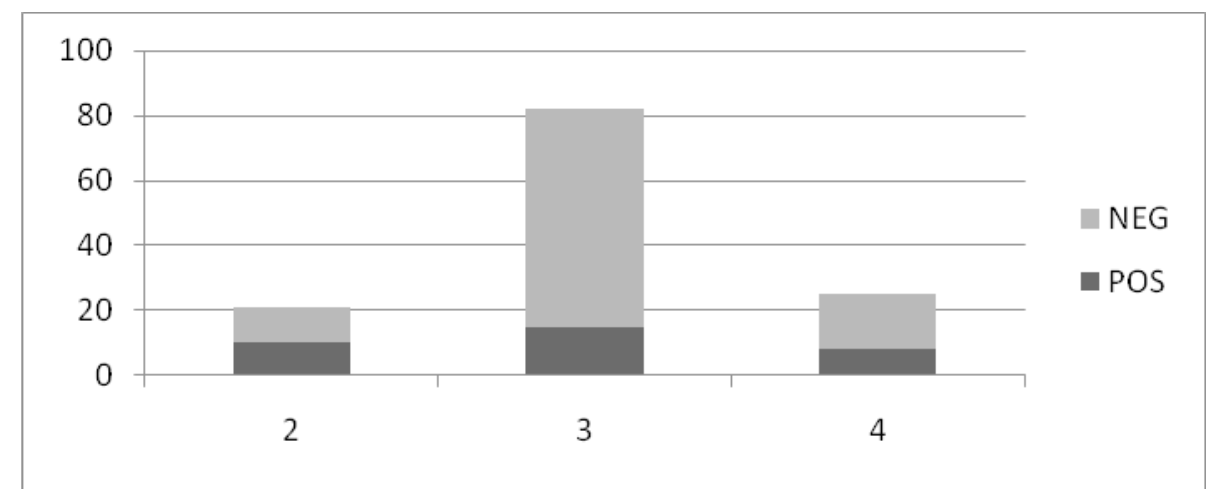

Fig. 1. Distribución de equinos positivos y negativos por Condición Corporal.

Los estudios revisados no presentan resultados desde la CC, y sí desde la sintomatología, lo que genera divergencia entre los datos. Si se establece el adelgazamiento como un síntoma se puede considerar que de los animales sin sintomatología (CC 3 y $4=107$ ) el $21.5 \%$ fue seropositivo y de los que presentaban sintomatología (CC 2) el $47.6 \%$ dio positivo, los datos son similares a los de Poconé, Brasil (21).
El análisis con la prueba Chi cuadrado $(\mathrm{P}<0.05)$ determinó relación significativa entre la edad y la prevalencia del virus. En animales menores de 5 años $(<5)$ fue del $5 \%$; en mayores de 10 años ( $>10$ ) fue del $14.29 \%$, y en los animales entre 5 y 10 años (5-10) fue considerablemente mayor, con el $33.33 \%$. Esta relación se presenta debido al tiempo de exposición de los animales durante su vida a vectores y a las prácticas de manejo realizadas por los propietaris (23).

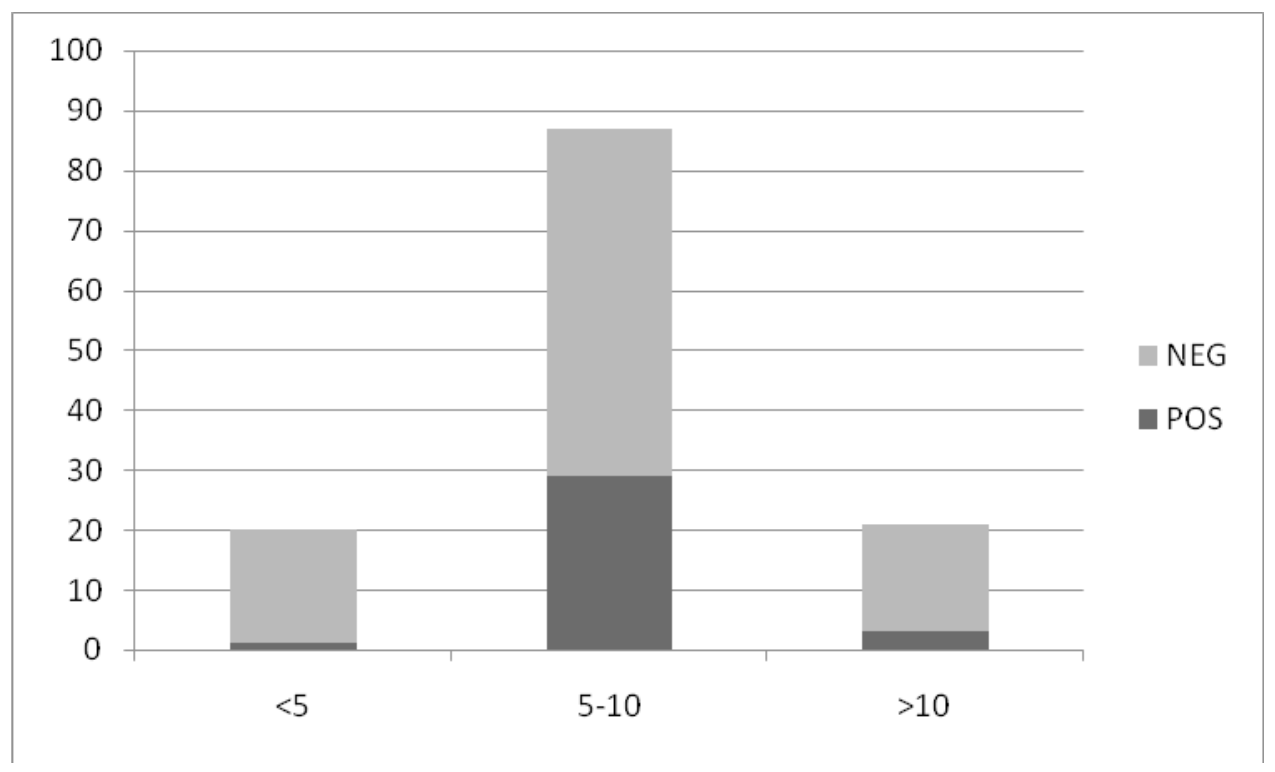

Fig. 2. Distribución de equinos positivos y negativos por edad.

Estos resultados coinciden con los encontrados en Pantanal, Brasil (23), donde se estableció que la edad es un factor de riesgo, pero se debe tener en cuenta el tipo de trabajo al que se exponen los animales en edad productiva, cuya mayor población está en el rango de 5 a 10 años.

Dentro del análisis por comunas se encontró que se registraron animales de 3 de ellas, de las 4 
existentes en el municipio (Figura 3). La prueba Chi cuadrado $(\mathrm{P}<0.05)$ no encontró relación significativa al respecto; sin embargo, en el análisis descriptivo se encontró prevalencias similares en las comunas nororiental y sur, con $27.94 \%$ y $29.73 \%$, respectivamente, las cuales difieren con la de la comuna norte, donde la prevalencia fue de $13.04 \%$.

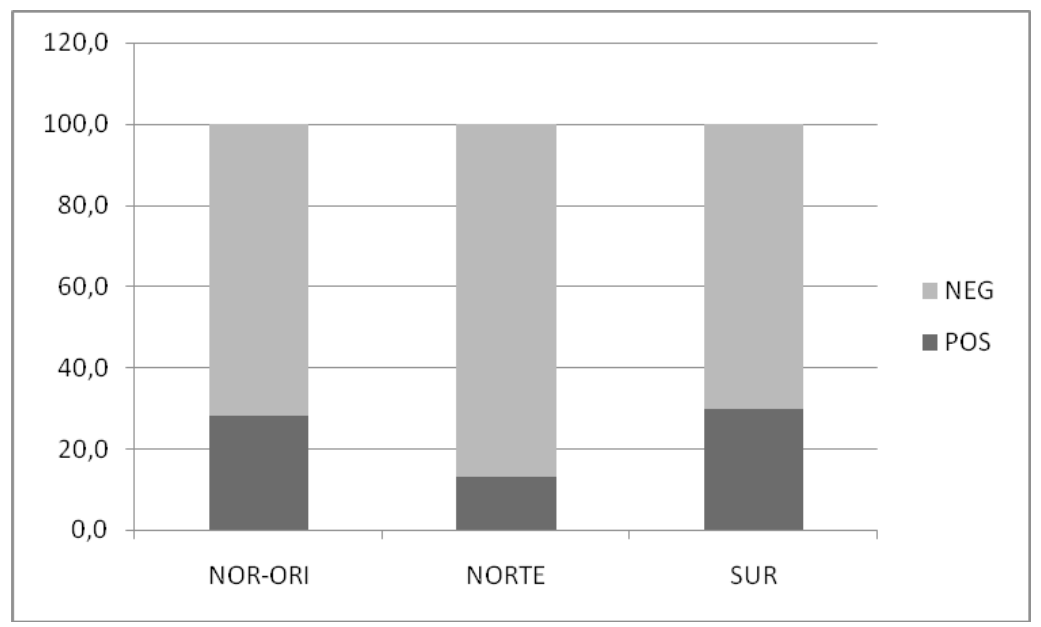

Fig. 3. Distribución de equinos positivos y negativos por comunas.

Es de aclarar que el censo poblacional registrado por la brigada no es homogéneo, lo que podría influir en la dinámica epidemiológica del virus, al presentar mayor densidad poblacional, que permite una cobertura considerable de los vectores, resultados opuestos a los encontrados por Borges et al. (2013) en Poconé, Brasil (21).

\section{Conclusiones}

Debido a la facilidad de diseminación del virus y a que la AIE no es considerada por las entidades responsables una enfermedad de reporte ni sacrificio obligatorio, la prevalencia de esta en animales ajenos al gremio analizado podría incrementarse, lo que puede generar pérdidas económicas considerables en los sistemas de producción y manejo de estos animales, además de la afectación considerable del bienestar animal, al trabajar equinos enfermos y en malas condiciones.

Las condiciones socioeconómicas del gremio dificultan el control de la AIE, por lo tanto, se deben implementar protocolos sanitarios más estrictos y eficaces, como el aislamiento y la eliminación efectiva y de manera segura de animales infectados, y, a futuro, establecer un programa de sustitución de vehículos de tracción animal en la ciudad, eliminando de esta forma un foco importante de la enfermedad.

\section{Agradecimientos}

Al Laboratorio Almacén INSUAGRO, por las pruebas, y al médico veterinario y zootecnista Jhonathan Alberto Salazar, profesional encargado del COSO municipal de Florencia, por su acompañamiento en las brigadas de salud animal.

\section{Referencias}

(1) Bendali-Ahcène $S$, Monier JC, Fontaine $M$, Greenland T, CadoréJL. Flow cytometric analysis of blood lymphocyte phenotypes in horses infected with the equine infectious anemia virus. J-evs. 1995; 15(8): 360-364. DOI: http:// dx.doi.org/10.1016/S0737-0806(07)80548-X.

(2) Radostits O, Gay C, Blood D, Hinchcliff K. Medicina Veterinaria: Tratado de enfermedades del ganado bovino, ovino, porcino, caprino y equino. Madrid: McGraw-Hill - Interamericana de España; 2002. 
(3) Beer J. Enfermedades infecciosas de los animales domésticos. Tomo I. Zaragoza: ACRIBIA; 1987.

(4) Rodrigues TR, Avanza MFB, Zappa V. Anemia infecciosa equina. Revista Científica Electrónica de Medicina Veterinaria. 2009; VII(12).

(5) Cook RF, Leroux C, Issel CJ. Equine infectious anemia and equine infectious anemia virus in 2013: A review. Veterinary Microbiology. 2013; 167(1): 181-204. DOI: http://dx.doi.org/10.1016/j.vetmic.2013.09.031.

(6) Junqueira MM, Paes AC. Anemia Infecciosa Equina. Vet. e Zootec. 2011; 18(2): 197-207.

(7) González FJ. Anemia Infecciosa Equina (AIE): presentación de un cuadro clínico. Revista Electrónica de Veterinaria. 2011; 12(10): 1-13.

(8) Colham TP, Mayhew LGJ, Merritt MA. Equine medicine and surgery (5ta edición). USA: Mosby; 1999.

(9) Organización Mundial de Sanidad Animal. Anemia Infecciosa Equina. 2013

(10) Organización Mundial de Sanidad Animal. Anemia Infecciosa Equina. 2015.

(11) Instituto Colombiano Agropecuario (ICA). Resolución 676 de 2015. 2015.

(12) Instituto Geográfico Agustín Codazzi (IGAC). Aspectos ambientales para el ordenamiento territorial de occidente del departamento del Caquetá. Tomo VI. Colombia: IGAC; 1993.

(13) Ruiz L, Valle E, Pérez O, Jiménez R. Condición corporal en equinos. Rvta ACPA. 2002; $4: 31$.

(14) Orsini JA, Divers TJ. Manual de Urgencias en la Clínica Equina: Tratamientos y Técnicas. Madrid: Harcourt; 2000.

(15) Instituto Colombiano Agropecuario (ICA). Laboratorios Registrados y Autorizados ICA. 2014.
(16) Mondragón IJ, Tafur LA, Muñoz JI, Gallego MI. Prevalencia de Anemia Infecciosa Equina (AIE) en équidos de tracción de Bogotá D.C., Colombia. Rev. Zooc. 2015; 2(Supl. 1): 7.

(17) Ruiz J, Cruz A, Reyes E, López A, Góngora A. Asociación Serológica de la Rinoneumonitis Viral Equina y la Anemia Infecciosa Equina. Rev. MVZ Córdoba. 2008; 13(1): 1128-1137.

(18) López J, Maestra O, Reza L. Estudio seroepidemiológico de la Anemia Infecciosa Equina en caballos criollos de paso en las pesebreras del municipio de Montería, Córdoba. Rev. MVZ Córdoba. 2000; 5(2): 20.

(19) Sarmiento P, Quijano M. Prevalencia del virus de la Anemia Infecciosa Equina (AIE) en dos poblaciones de caballos de trabajo de los departamentos de Chocó y Guajira. Colombia. Univ. Sci. 2005; 10(2): 55-60.

(20) Desquesnes M, Rocque S. Los tábanos de las Guyanas. Biología, morfología e importancia en la producción y métodos de control. Venezuela: IICA Biblioteca. 1994.

(21) Borges AM, Silva LG, Noqueira MF, Oliveira AC, Segri NJ, Ferreira F, Wilter R, Aguiar DM. Prevalence and risk factors for Equine Infectious Anemia in Poconé municipality, northern Brazilian Pantanal. Res Vet Sci. 2013; 95(1): 76-81. DOI: http://dx.doi.org/10.1016/j. rvsc.2013.02.011.

(22) Perotta J, Cassaro E, Sequetin E, Deconto I, Triches $\mathrm{P}$, Jayme T, Bonacim J, Costa R, Welker A, Barros I. Anemia infecciosa equina em cavalos carroceiros de áreas urbanas do sul do Brasil. Ciências Agrárias. 2015; 36(6 - Supl. 2): 4357-4360. DOI: http://dx.doi.org/10.5433/ 1679-0359.2015v36n6Supl2p4357.

(23) Silva R, Dávila A, Iversson L, Abreu U. Equine viral diseases in the Pantanal, Brazil. Studies carried out from 1990 to 1995 . Revue d'Élevage et de Médecine Vétérinaire des Pays Tropicaux. 1999; 52 (1): 9-12. 